Sergio Romano, La foi et le pouvoir. Le Vatican et l'Italie de Pie IX à Benoît XVI

Trad. de l'italien par Anne Guglielmetti. Paris, Buchet-Chastel, 2007, 153 p.

\title{
Michel Ostenc
}

\section{CpenEdition}

Journals

Édition électronique

URL : http://journals.openedition.org/assr/15923

DOI : $10.4000 /$ assr. 15923

ISSN : $1777-5825$

Éditeur

Éditions de l'EHESS

Édition imprimée

Date de publication : 1 juin 2008

Pagination : 191-321

ISBN : 978-2-7132-2190-3

ISSN : 0335-5985

Référence électronique

Michel Ostenc, "Sergio Romano, La foi et le pouvoir. Le Vatican et l'Italie de Pie IX à Benoît XVI », Archives de sciences sociales des religions [En ligne], 142 I avril-juin 2008, document 142-50, mis en ligne le 26 novembre 2008, consulté le 21 septembre 2020. URL : http://journals.openedition.org/assr/15923 ; DOI : https://doi.org/10.4000/assr.15923

Ce document a été généré automatiquement le 21 septembre 2020

(c) Archives de sciences sociales des religions 


\section{Sergio Romano, La foi et le pouvoir. Le Vatican et l'Italie de Pie IX à Benoît XVI}

Trad. de l'italien par Anne Guglielmetti. Paris, Buchet-Chastel, 2007, 153 p.

Michel Ostenc

1 Cet essai de Sergio Romano est la traduction d'un livre paru en 2005 à Milan (Longanesi Editore) sous le titre «Libera Chiesa. Libero Stato? Il Vaticano e l'Italia da Pio IX a Benedetto XVI ». Cet intitulé reprenait ironiquement la fameuse formule de Cavour : une "Église libre dans un État libre », pour mieux dénoncer une présence excessive du clergé dans la vie politique italienne d'aujourd'hui. L'ouvrage revient sur un sujet largement débattu dans le célèbre volume d'Arturo Carlo Iemolo, Chiesa e Stato in Italia dall'unificazione a Giovanni XXIII (Turin, 1956), devenu un classique en France sous le titre L'Église et l'État en Italie. Du Risorgimento à nos jours (Paris, Seuil, 1960).

2 La "Question romaine » a toujours pesé sur l'unité italienne, les États pontificaux représentant un obstacle à la création d'une monarchie nationale dans le pays. La nécessité de leur disparition interdisait par ailleurs tout soutien de la religion au processus d'unification du pays. Si bien que le Risorgimento a connu plusieurs étapes d'une véritable guerre civile, des millions d'Italiens appartenant à toutes les couches de la société restant fidèles aux directives de l'Église. La loi des Garanties du 2 mai 1871, survenant au lendemain de l'occupation de Rome par les troupes italiennes, était pourtant destinée à montrer qu'il ne s'agissait pas d'asservir la papauté. Elle reconnaissait au pape, qu'elle considérait comme un souverain, le droit d'avoir des ambassadeurs accrédités auprès de sa personne ; le Saint Siège conservait la possession de la cité du Vatican, des palais du Latran et de la Chancellerie, ainsi que la villa de Castel Gandolfo. La loi lui attribuait en outre une forte rente annuelle et le gouvernement italien renonçait à ses pouvoirs sur l'Église dans le pays et à sa participation au choix des évêques. Pie IX n'en refusa pas moins d'accepter cet acte unilatéral, excommunia ses auteurs et se déclara prisonnier au Vatican. Si bien que la classe politique italienne au pouvoir, même lorsqu'elle appartint à la Gauche historique de Depretis, fit l'impossible pour éviter d'accentuer la division du pays. 
3 L'auteur multiplie les exemples historiques démontrant la présence encombrante de la "Question romaine » jusqu'au niveau des décisions politiques de la classe dirigeante libérale au pouvoir à Rome. Le nationalisme populiste qui poussa l'Italie à conquérir la Libye comportait un fort courant catholique et le pacte Gentiloni de 1913 conclu contre la poussée électorale socialiste introduisit au parlement des députés dévoués à la cause $\mathrm{du}$ pape. Les groupements politiques catholiques représentaient désormais un facteur entièrement nouveau qui pesait sur les rapports de l'Église et de l'État. La présence du Saint-Siège gênait aussi la diplomatie italienne et le ministre des Affaires étrangères, Sidney Sonnino, redoutait en 1915 que l'Autriche ne cédât le Trentin au pape afin de lui permettre d'en négocier la rétrocession à l'Italie. L'hostilité du Vatican à l'État libéral incita ensuite la Parti populaire de Don Sturzo à s'opposer au retour de Giolitti au pouvoir en 1921 et 1922, faisant ainsi indirectement le jeu de Mussolini. Il est d'ailleurs significatif que l'Église ait accepté de mettre un terme à la "Question romaine » en négociant avec le Duce, personnage dégagé des "préoccupations libérales » comme le disait Pie XI et qui avait détruit le régime responsable de l'annexion de Rome au royaume d'Italie. Les Accords du Latran semblaient régler tous les problèmes. Le Vatican et ses dépendances constituaient désormais un État souverain, le pape reconnaissant en contrepartie Rome comme capitale de l'Italie ; mais, à côté de ce traité politique, un concordat donnait à l'Église une position privilégiée dans le pays en lui attribuant l'état civil et des privilèges en matière scolaire. Alors que tout s'effondrait autour d'eux pendant la guerre, les Italiens retrouvaient avec la foi l'autorité séculaire de la papauté dans les affaires de la péninsule. Si bien que les communistes, conscients de cette évolution, se montrèrent conciliants dans les débats de l'assemblée constituante. Le Saint-Siège tenait au maintien des Accords du Latran lorsque fut discuté l'article 7 de la Constitution sur les relations de l'Église et de l'État. Togliatti et le catholique Dossetti finirent par s'entendre pour en faire une entité indépendante et souveraine. Le concordat n'était certes pas immuable puisqu'il sera modifié en 1984 ; mais Sergio Romano estime qu'il existait entre les Accords du Latran et la Constitution de la République italienne un verrou impossible à ouvrir sans le consentement de l'Église. Togliatti avait compris qu'on ne gouvernait pas l'Italie contre une opinion populaire encore en majorité catholique. La campagne électorale battait son plein pendant que l'Union soviétique assiégeait les secteurs occidentaux de Berlin, et l'alliance socialo-communiste avait des chances de l'emporter. L'Église s'impliqua totalement dans la bataille électorale, mobilisant vingt mille "comités civiques » et trois cent mille militants de l'Action catholique pour défendre les candidats de la Démocratie chrétienne. Comme le notait Arturo Carlo Iemolo, le bulletin de vote de l'électeur catholique conférait à l'Église des possibilités d'intervention dans la vie publique plus étendues que les arrangements antérieurs passés avec les souverains italiens. Elle entreprit alors une reconquête de la société qui atteignit son apogée au début des années 1950 lorsque le Saint-Siège tenta d'imposer au chef du gouvernement Alcide De Gasperi une alliance avec les monarchistes et les néo-fascistes du Mouvement Social Italien (MSI).

4 Le virage du Vatican dans les années soixante se fit d'abord sentir en politique intérieure. La gauche s'était emparée des rênes de la Démocratie chrétienne et elle souhaitait gouverner avec les socialistes; mais Sergio Romano ne considère pas cette ouverture au centre-gauche comme une prise de distance du parti catholique avec le Saint-Siège. L'élection de Giovanni Battista Montini au trône pontifical facilita au contraire un rapprochement, tant le nouveau pape connaissait bien le groupe dirigeant 
démocrate chrétien qu'il avait largement contribué à former. Le cardinal Agostino Casolari, diplomate particulièrement actif sous trois pontificats, fut le principal protagoniste de l'« Ostpolitik » du Vatican. Il s'agissait d'éviter un affrontement frontal avec les régimes communistes en créant pour l'«Église du silence» des espaces de liberté qui ont sans doute profité à la hiérarchie catholique polonaise et aux communautés évangéliques d'Allemagne de l'Est. Le dialogue ouvert par le Saint-Siège avec les régimes athées fut suivi d'une ouverture comparable de la politique étrangère italienne. Les accords de coexistence patiemment négociés par la diplomatie vaticane figurent parmi les facteurs favorables à la signature du concordat de 1984. D'autres éléments y contribuèrent, et notamment l'action de Jean-Paul II, qui ne nourrissait plus à l'égard de l'Italie ce sentiment de possession propre à ses prédécesseurs. Le catholicisme n'était plus religion d'État, l'enseignement religieux devenait facultatif et les tribunaux ecclésiastiques perdaient leur compétence exclusive sur le mariage ; mais le concordat n'en garantissait pas moins un statut privilégié à l'Église catholique dans le pays. La disparition de la Démocratie chrétienne n'a pas alarmé le Saint-Siège. Elle lui avait certes permis de mieux contrôler la société italienne pendant la guerre froide, mais en contraignant parfois l'Église à fermer les yeux sur des décisions qu'elle désapprouvait. Le Vatican devenait paradoxalement plus libre et les catholiques, dispersés entre les partis, pouvaient faire entendre leur voix partout. L'auteur estime que la liberté et l'autorité de l'Église en sortirent renforcées, au point de l'inciter à revendiquer l'identité catholique de l'Italie.

Le grand journaliste Indro Montanelli affirmait que les démocrates chrétiens italiens avaient constamment miné les gouvernements qu'ils ne dirigeaient pas, manifestant ainsi leur absence de sens de l'État. Sergio Romano lui emboite le pas en affirmant qu'ils ont combattu avec acharnement les deux gouvernements de Massimo D'Alema et se sont efforcés de détruire politiquement celui de Silvio Berlusconi. Ils ont par contre accepté Romano Prodi qui est l'un des leurs. En fait, les dirigeants démocrates chrétiens resteraient profondément convaincus que le catholicisme représente le tissu conjonctif de l'identité nationale italienne et la seule idéologie capable de maintenir l'unité du pays. Les plus libéraux d'entre eux ont certes salué la fin du pouvoir temporel du pape et voudraient que l'Église laissât aux laïques la gestion de l'État; mais l'Église romaine représenterait pour eux plus qu'une confession religieuse. Elle serait le dépositaire d'une mémoire où reposent les caractères fondamentaux de la Nation. Sans doute, l'aide de l'Église aux catholiques est-elle précieuse sur le plan électoral; mais leurs rapports avec le Saint-Siège vont bien au-delà de cet aspect utilitaire et ce néoguelfisme a des conséquences politiques. Les catholiques n'aiment pas le système bipolaire qui les divise en deux camps opposés et affaiblit leur influence. Ils lui préfèrent la proportionnelle et aspirent à reconstituer un grand parti du centre dont ils représenteraient l'épine dorsale. Ce régime politique est sans doute moins adapté aux décisions rapides qu'exigent la société et l'économie de notre époque; mais Sergio Romano juge le rapport des catholiques avec la modernité empreint d'ambiguïté : ils seraient conscients de son caractère inéluctable, tout en craignant qu'elle n'altère l'identité nationale. L'auteur ne veut pas pour autant limiter le droit d'expression des autorités du Vatican; mais il estime que leurs déclarations sont exploitées par les hommes politiques à des fins électoralistes. Il rejoint ainsi l'opinion d'Arturo Carlo Iemolo qui se demandait si l'obéissance des catholiques au Saint-Siège ne leur interdisait pas de s'insérer dans la vie démocratique d'un État moderne et si leur unité politique n'était pas de nature à freiner le développement du pays. 
Le conflit de l'Église et de l'État a certes conduit le Saint-Siège à s'opposer au Risorgimento et à ses hautes vertus civiques et morales; mais il s'agissait de causes contingentes liées à une situation historique et l'Église d'aujourd'hui n'est plus celle du «Syllabus» ou du dogme de l'infaillibilité pontificale. Elle a montré sa capacité d'adaptation aux idées modernes en suivant une évolution de la société qui a considérablement contribué à sa sécularisation. La science a profondément changé elle aussi et l'intérêt de beaucoup d'intellectuels pour l'Église vient du fait qu'elle exprime des préoccupations contemporaines. Dans un pays de tradition catholique, il est normal que les chrétiens et les non-croyants s'interrogent sur les problèmes moraux posés par la vie quotidienne en les confrontant aux déclarations de l'Église. Des sujets comme l'euthanasie, l'avortement, la bioéthique ou la famille sont inévitables dans une société en pleine mutation. Il ne reste plus beaucoup de domaines sur lesquels les individus peuvent bâtir leurs espoirs et construire leur salut. L'insécurité restera quoi qu'il arrive dans le monde instable où nous vivons. Il faut donc trouver une voie qui la rende supportable en permettant l'accès à un bonheur moins incertain. La propension du christianisme à s'interroger sur le sens de la vie et de la solidarité humaine en est une. Sans doute est-il plus simple de prêcher la morale que d'annoncer les fondements de la révélation. Ainsi s'explique la facilité avec laquelle les non-chrétiens rejettent tout ce qui s'oppose à la vulgate de la libéralisation des mœurs; mais l'Église ne définit pas seulement le bien et le mal en fonction de ses dogmes religieux, elle le fait aussi au nom d'une conception universelle de l'homme. Dès lors, son engagement à tous les niveaux de la société ne peut trouver sa pleine réalisation sans une concrétisation politique qui pose à nouveau l'éternelle question de ses rapports avec l'État. Sergio Romano dénonce à juste titre l'utilisation du christianisme à des fins politiques qui transforme la religion en instrumentum regni; mais on ne saurait s'en prévaloir pour mettre en doute le sens civique des chrétiens qui occupent des fonctions publiques. Ces difficultés viennent sans doute de la crise de la politique qui n'est plus aujourd'hui une technique réservée à des spécialistes. Elle touche désormais des problèmes éthiques essentiels pour l'avenir de l'humanité qui concernent toutes les composantes de la société civile et ne peut exclure ses représentants les plus avertis au niveau moral. Ce n'est donc pas l'Église qui outrepasse ses droits ; c'est plutôt la politique qui s'avère incapable d'exercer les siens. 